\title{
ART AND WATER COLLABORATION: INTERVIEW
}

\section{INTRODUCTION (Anne Marie Basquin)}

I knew right away I wanted to work with Bryce Peebles, a marine scientist from Otago University, specialising in deep-sea ecology, biomineralization, and ocean acidification. He shared my fascination with the deep sea and I sensed I could learn so much about ocean acidification and the changing oceans, an area I had been interested in for a long time. I was eager to see how we could weave our shared interests with our individual talents of observation and research, art and writing, in a way that might inspire and inform the public.

Drawing on Bryce's work for inspiration, I explored. I took underwater images at noon from inside rock pools on the South Otago coastline, creating submerged still-lifes of creatures that experience a process akin to ocean acidification during any low tide at peak sunlight hours. Hours spent peering into these pools led to long exposures at dusk, capturing the tide on its way in, leading to even longer exposures of star trails rising over the ocean, and rock pools glittering in the star shine beneath.

The deep-sea canyon maps that Bryce sent me led me deeper. I sketched and traced and coloured their lines until my hand had memorized them. Neither Bryce nor I could pick an area to focus and refine: the rock pools? The stars? The canyons? What we kept coming back to was deep time and the intrinsic connection between all things. I imagined epochs beginning and ending, and couldn't get the colours of a different world out of my mind. Nor the whales I swam with in the South Pacific, whose migratory routes pass right through the deep canyons I had been tracing.

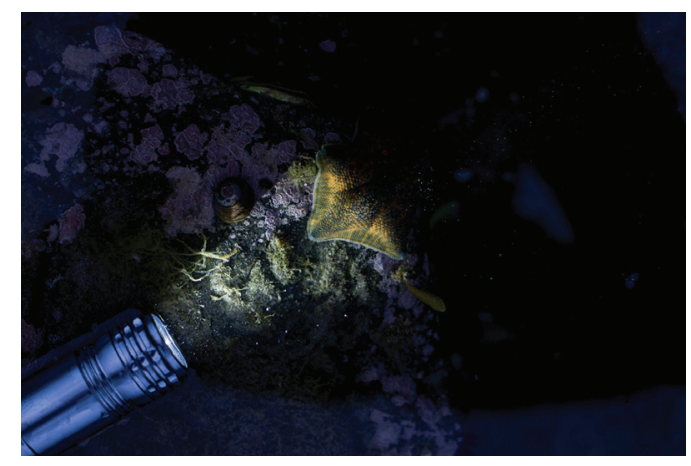

Figure 1. Exploring rock pools by torch light. Photograph: Anne Marie Basquin. 


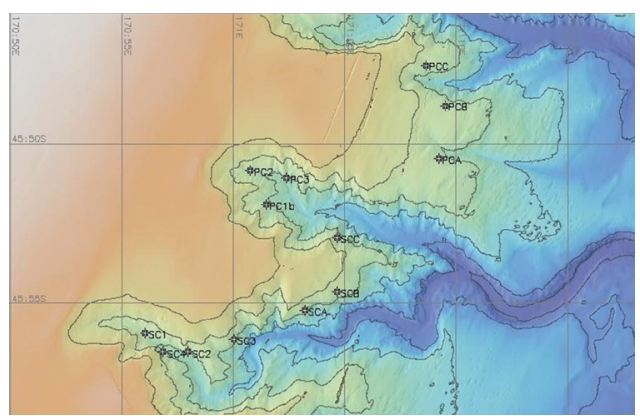

Figure 2. Deep canyons off the coast of Otago. Photograph: Bryce Peebles.

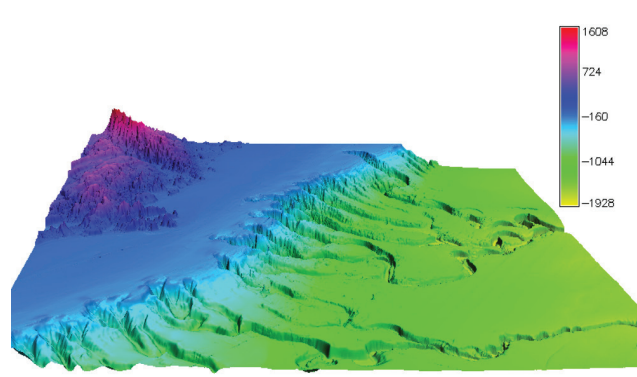

Figure 3. 3D map of canyons off the coast of Otago. Photograph: Bryce Peebles.

Bryce and I set out to interview each other in the hopes of covering our vast interests and the web of connection that weaves them together (and still we may have only touched on our most cherished issues). Each time we refined our project, we zoomed in, and the material grew richer and wider. I had the sense that we stood on a great precipice, looking over, and that neither of us had the desire to limit or reduce what we saw there. We weren't afraid of the deep, only fascinated.

As you wade through our interview, you might feel as though you are skirting the edges of tidal pools at dusk, peering into crevices and under rocks, at starfish and Neptune's necklace. In between glances at the sky, to gauge how much light is left, you may have the sense that you have gained entrance to another world, the vastness of which may never be fully realized. May this feeling remind you of your place on this planet, at the very edge of the Pacific ocean, vulnerable to the changing tides and the waxing and waning of the moon. We stand here together, looking forward, on the edge of everything.

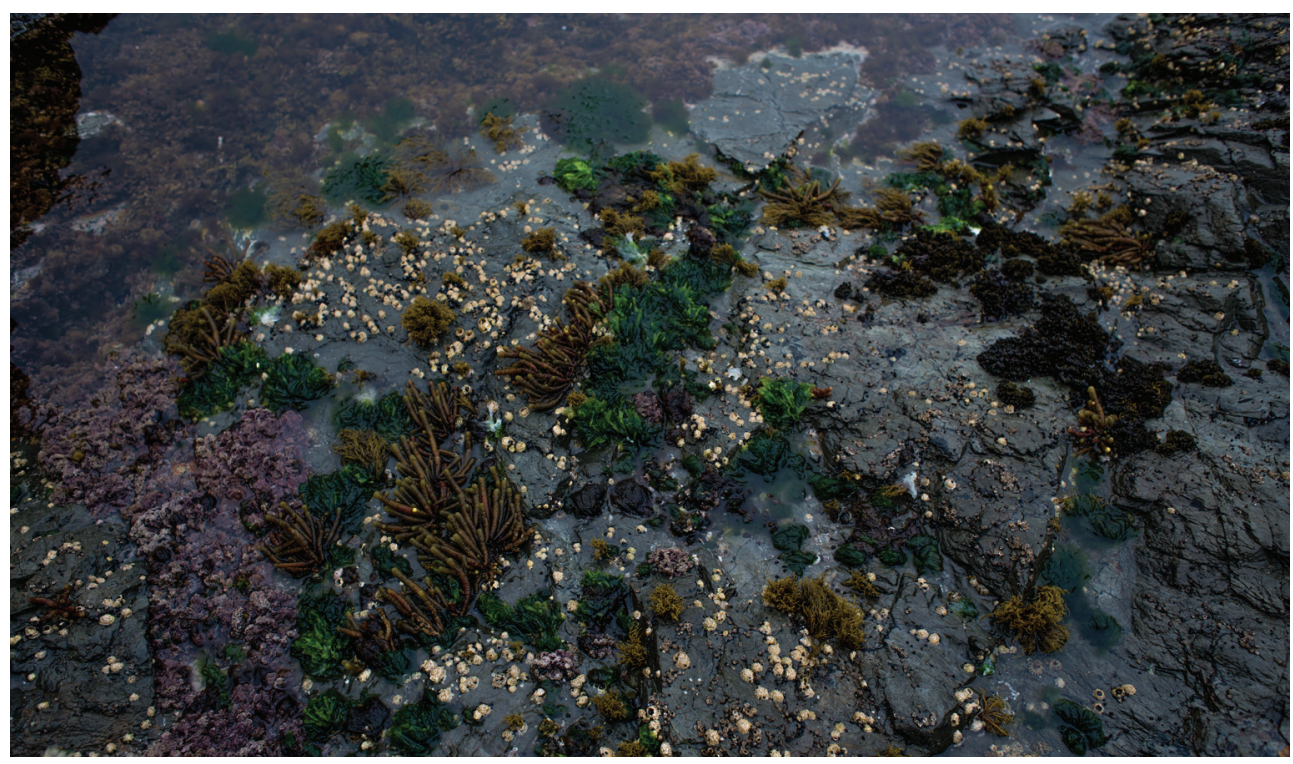

Figure 4. Rock pools at low tide, Neptune's necklace. Photograph: Anne Marie Basquin. 


\section{TRANSCRIPTION: ART QUERIES SCIENCE}

AMB: What led you to study deep-sea ecology?

BP: I've been interested in the deep sea since I was young. At first, I was interested in dinosaurs. Then I learned we didn't know a lot about extinct or current marine organisms. Also, I discovered we knew more about space and our moon than we do the deep sea. In the US, where I'm from, exploration is not a well-funded area of research. That's not the case in NZ and that fact helped guide me to an MSc at Otago, where I detailed the ecology of four submarine canyons off the Otago Peninsula. That allows us to analyse anthropogenic effects (mining, dredging, etc.) on the canyons' biodiversity.

AMB: Were there already established professors at Otago researching the deep sea?

BP: There was a well-established professor who did a lot of deep-sea ecology, Keith Probert. He's well recognised and it was fun to see what his other students were doing as well. I wanted to do my PhD in the same topic but that didn't work out because he was retiring. I ended up approaching the HOD and happened to find a project she had on chitons that I was interested in. Their magnetic teeth drew me in. The project was initially on how ocean acidification affects these molluscs, but about a year in, someone made an off-hand comment of how chitons are rarer than expected in the fossil record. I thought that was odd since the filters that preserve an organism are nonrandom (i.e. does your body have a skeleton, shell, or hard part)? The boxes chitons and other molluscs "tick" were the same, so in theory chitons should be as common as any other mollusc. I was curious as to why they were relatively rare and it quickly turned into the main topic of my $\mathrm{PhD}$.

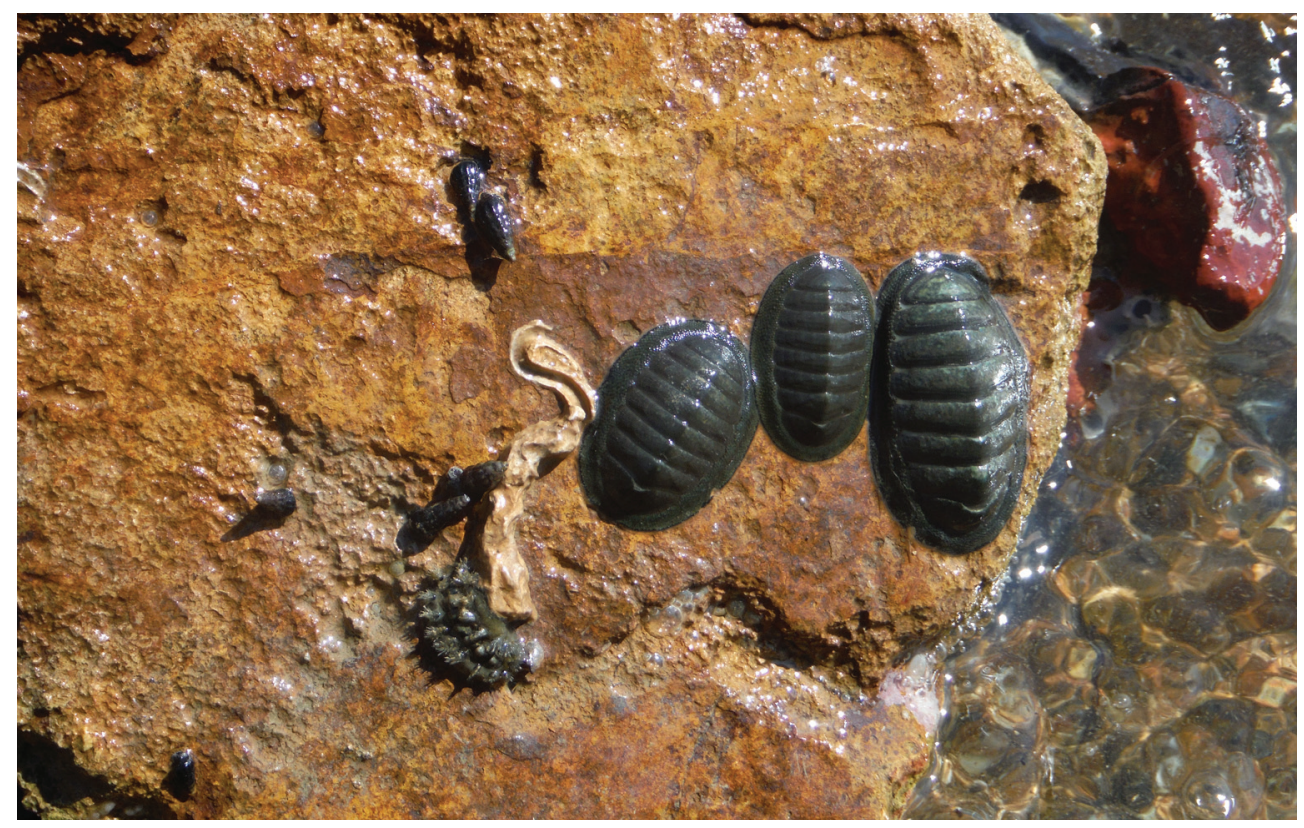

Figure 5. Chitons and snails on rocks. Photograph: Bryce Peebles. 
AMB: And what did you find?

BP: What it boils down to is that chitons do something unique among the molluscs - they incorporate sensory tissue into their shell. When they die, that nerve tissue decomposes, which causes localised dissolution and helps break the shell apart. So part of their missing record is not only caused by the shell being broken down to a higher degree than other molluscs, but also that surviving material can be harder to identify as a chiton (much less identified down to genus or species level). Their smaller size also hinders them when trying to endure abrasion, dissolution, and other destructive forces. That's the summary of those three years of research!

AMB: Could you talk about the visual tissue and your more recent work with chitons?

BP: Sure, the other crazy thing chitons do is that they form their lenses out of aragonite - a polymorph of calcium carbonate - meaning they have eyes made of rock. Some other organisms have eyespots made of rock so they can detect light/dark but cannot form images. Chitons can actually see incoming predators and other animals. There was some debate on whether chitons could actually form images with their ocular structures and it turns out they have anywhere from 20/30 to 20/80 vision. We took images of several things through a chiton lens, including a Snellen chart - the same chart with letters that you'd find at the optometrists - to determine their visual acuity.

AMB: And these lenses are all over the shell. How many lenses are we talking about?

BP: For one individual there are hundreds of lenses. One valve can have $50-80$ in a "v" shape on the top. I learned they could see me as I was collecting them. I was able to trick them into moving onto a scalpel, which was much easier than trying to pry them off.

AMB: When sampling the deep sea, did you work in the water or from a boat?

BP: The canyons are hundreds to thousands of metres down. You would need a submersible vessel to reach them. It's a lot of checking radar and GPS to make sure you are where you want to be. Once we were on the slope, we sent a dredge over to collect about a $0.5 \mathrm{~m}^{2}$ of sediment and some organisms. We took samples from the slope and the trench of the canyons. We sampled from 800-2000m and it took about 20 minutes to get the dredge down and another 20 to get it back up, which was hard when we failed to collect anything.

AMB: Can you describe what the world is like down there?

BP: The first thing is that it is very dark. The floor is silty, sandy, and barren, similar to a desert. It's flat and kind of boring until you get into the canyons where more organisms begin to appear. The higher biodiversity is due to increased nutrients being funnelled down from above and brought up through the canyons through deep nutrient-rich water. Very different to sampling along the beach, which is similar to rock or shell hunting but with a bit more paperwork to make sure you aren't poaching.

AMB: Did you grow up by the sea? 
BP: I grew up in the LA area, which is mostly big city and desert. The beach was 3-4 hours away and was mostly sandy so there weren't a lot of rock pools. Whenever I got to do an educational program or visit a place with rock pools it was really interesting because I could see and interact with the animals I read about. Learning to scuba dive and see what was another world was magical and was the moment I knew I was on the right path.

AMB: Can you talk about the research done at White Island?

BP: Yes, I didn't get to go because I had a conference at the same time, but it was a large group of people that went with a "fleet" to White island. The group was split into biological, geological, and chemical teams that sampled around the island for a week. There are coves that have $\mathrm{CO}^{2}$ seeps that reduce the $\mathrm{pH}$, and coves that have no seeps. So this was a natural laboratory to see what happens if ocean acidification continues. Each team could sample from present and "future" sites to see if our models held up, what organisms are present, etc. The main idea is that $\mathrm{CO}^{2}$ is getting sucked up by the ocean, and that drives the $\mathrm{pH}$ down, which is hard on marine organisms that form shells. Their shells readily dissolve in lower pHs. Unsurprisingly, this is not great for them since a weaker shell makes them more vulnerable to predation and forces them to put energy into forming a new shell instead of mating, metabolism, and other things living organisms need to do. Since dissolution already removes shells from the fossil record and it is becoming amplified, I wonder how much information we are going to lose. Without getting into too much detail, marine calcifiers pull cations/anions from the water column to form their shell. Their shell locks in these ions they pull out of the water, and the proportion of ions tells us several chemical and physical qualities of the water. As long as we have the shell, we can use those captured ions to read a record of the ocean. A more acidic ocean may work to remove that record.

AMB: Is there a period of time in the earth's history that echoes the ecological changes caused by ocean acidification?

BP: Yes and no. Yes, because high acidity levels and temperature are things we've seen in the past. No, because the speed that it is changing is dramatically faster, so it's a rate problem. Say you're driving a car and when pulling out of the driveway you hit a wall. If you are going less than a $1 \mathrm{~km} /$ $\mathrm{hr}$ the main response is "oops". In the past the change was so slow organisms could adapt. When the car is travelling at $80 \mathrm{~km} / \mathrm{hr}$, suddenly hitting a wall is very different. We're travelling in the faster car. Millions of years to adapt is different from having to change within a generation or two. Organisms can't keep up.

AMB: What do you feel your role as a scientist is? Is it restricted to an observer/researcher role or do you have a desire to communicate and to interact with the community?

BP: $100 \%$, communication needs to be a part of it. Yes, most of it is researching and observing to find out how the world works. But that knowledge is useless locked away. Sharing ideas helps us move forward more quickly. There is also a responsibility to share knowledge with the public because it's their world too. If you want to take a more selfish ideology: the public put funds into it and deserve to know what we discover. A selfless ideology is that they share this world and the knowledge allows them to further engage with the world around them. The current political realm highlights why this is necessary. You don't have to be a scientist but being science literate to 
identify good-quality research is extremely helpful. Part of my job is highlighting what makes high quality research and how to look for red flags instead of just telling people what is good/bad.

AMB: Do you feel like you have many avenues to pursue this available to you as a scientist, or is this something you have to seek out?

BP: You have to go and find it mostly, the opportunities are there but they aren't emphasised, especially in the university system where academia is grant, publication and research focused. It's very easy to get locked into simply focusing on publishing due to pressure from the university and thinking that the information is public because it's published in a journal. But the general public doesn't know which journal to look at, and most of them are behind a paywall, so it's not really accessible. You need to look around the community, liaising with other departments and museums, and keep an eye out for opportunities.

\section{SCIENCE QUERIES ART}

BP: Why did you choose the canyon and ocean acidification research over the other topics available?

AMB: Much of the other research was land based and I wanted to work with water. When you were presenting, the words "deep-sea canyons" kept resonating in my mind. Then you mentioned ocean acidification and the changing oceans, topics I've been interested in and eager to learn more about for a long time. I realised you might be similarly diverse in your specialisation and that interested me.

BP: What is your process when taking a work of art from concept to creation?

AMB: It can be a really long process. This project had its beginning about seven years ago. I started writing a novel about whales and the changing oceans. When I started, I'd been thinking about going back to school and studying marine science - l'd always wanted to be a marine biologist. Once I started writing though, the story was enough. I was immersed in that world and learning so much. I was working at a camera store at the time and I started meeting all kinds of people interested in the ocean. I met ice scientists on their way to Antarctica and cetacean researchers and even people from Sea Shepherd - all these different people, passionate about different aspects of the ocean. I asked lots of questions and absorbed everything they were telling me and then l'd go home and write it all down. Eventually I heard about whale swimming and I started thinking about trying to go on a trip. It took me three years to get to Tonga - I can be a slow mover. The trip was life changing for me.

I'm trying to create a beautiful tale that's grounded in the real world, weaving in real science, theories and experiences - my own and others - of the marine environment, while at the same time offering an imaginative glimpse of what could happen, and how we might prevent that, or at least enjoy what we have better before it's gone. This project is the latest iteration of the concept that began with this story.

BP: You've mentioned Elizabeth Kolbert's work The Sixth Extinction as part of your inspiration. Do you have any other works that have influenced you, and was that the major influence of the colours that you used for these pieces? 


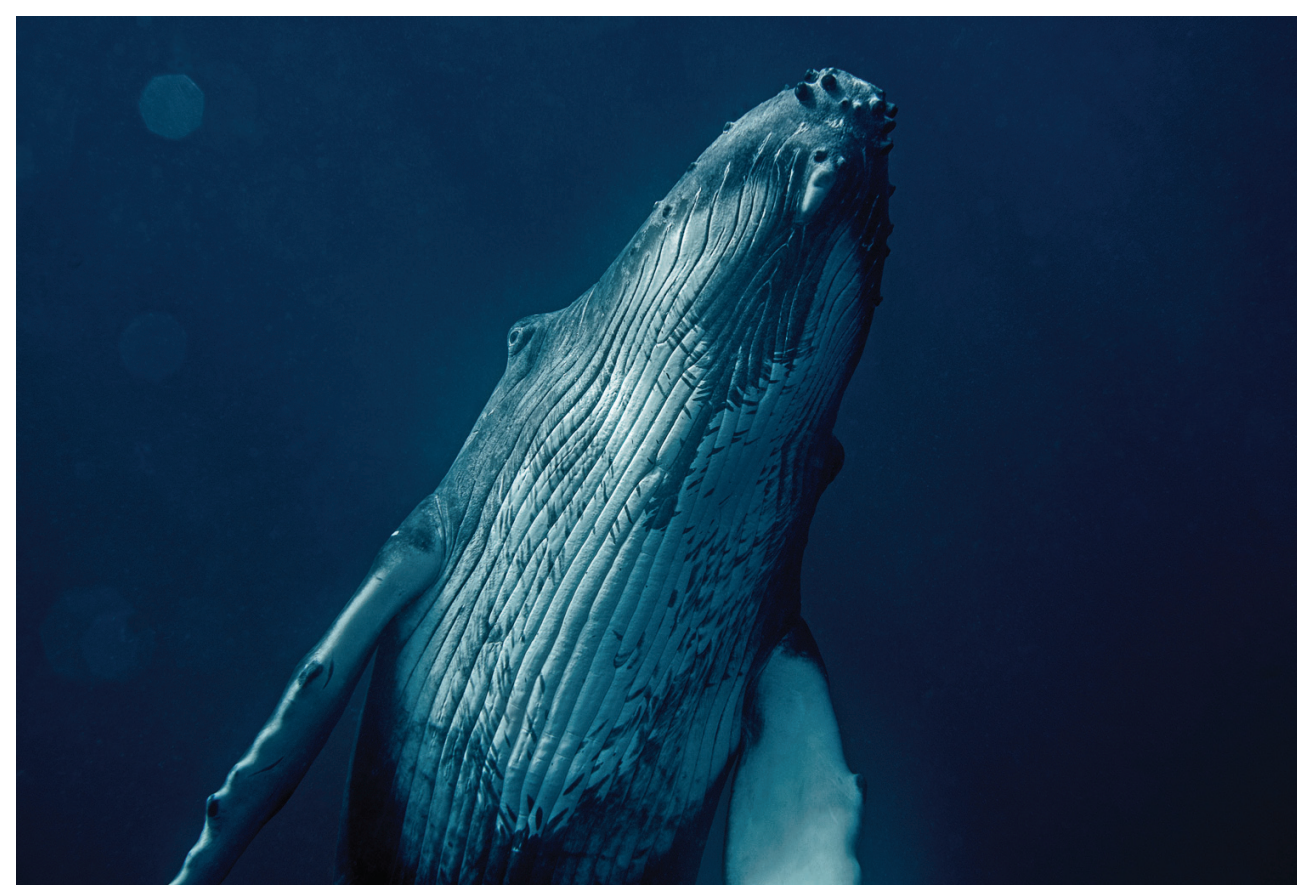

Figure 6. Whale calf. Photograph: Anne Marie Basquin.

AMB: That's a really good question. I couldn't begin to list the artists and writers that have influenced my life. The photographer Matt Draper has had a major influence on me. He's taught me everything I know about in-water interactions with marine mammals. His photographic work on humpbacks and other marine animals, and what he contributes as an artist to conservation in conjunction with Sylvia Early and her foundation, have been a huge inspiration to me.

For this particular project though, Elizabeth Kolbert's The Sixth Extinction was certainly the primary influence. The end-Permian era Elizabeth Kolbert refers to in her book is a time and place on the planet "where glassy, purple seas released poisonous bubbles that rose to a pale green sky." Along with its vivid colour palette, the image fulfils my interest in deep time. I moved here from the US when I was eleven, so there's a huge chunk of my past that is kind of lost in time. When difficult things happen that can be a struggle to process emotionally, they tend to be compressed and potentially transformed, over time, into really beautiful things. The colours speak to that for me. The image is fitting for where our planet may be heading and vivid enough to be memorable, or at least it was for me. To look back into deep time or far ahead into the future of our changing planet, requires exaggeration of what we know now and a little bit of imagination. I wanted to play with that by bringing to life on the canvas, in vastly exaggerated, living colour, real underwater scenes.

Colour has always been a part of my life and work, but it kicked back into my life in a big way when my Dad passed away in 2015. He's always been a big influence in my life in terms of art. He and my Mom have encouraged me to explore that part of myself without restraint. Once he died I needed a way to process my emotions and I started painting again, after years away from it. On the first 
trip I took to Tonga to swim with humpback whales, my friend Fizzy recorded the singers we came across. When I came home I painted to these recordings. I had the idea for the big whale paintings about a year before I ever painted one. It took me awhile to get the materials and the space and confidence together that I needed to actually do it. On the second trip to Tonga my photography went up another level and I came back and started the big paintings.

I enjoyed being part of a group of people (the artists and scientists collaborating for the Art+Water exhibition) all trying to do really neat things with a broad project base, but what meant the most to me out of everything was actually the creation of the artwork. It was being in the water, not knowing what I was doing at all and finding my way to expression via these different methods. This idea of valuing experience as its happening is something I'm passionate about communicating. Our experiences of the world are so finite and limited, but those limitations are there in order to open us up to sensation and connection. A lot of my art represents phenomenal experiences, so people are like, "Wow that's amazing!" But actually, before I experienced those moments, l'd had other experiences that were totally mundane, yet where I was just as immersed in the world. I remember, as a child, walking through the flowers with the dogs for example, collecting bugs and sticks. It's the same thing and it's not inaccessible.

BP: Exactly, that moment can be found pretty much anywhere on earth as long as you're connected to it. Those moments should really be treasured.

AMB: What I love about being in the water is it forces you awake into a connected space. You have to be completely present and relaxed in order to be safe. It took me a lot of dives to understand that the only way I was going to attain any kind of control was by relaxing. At the Mokoia wreck at Aramoana there are sea tulips and kelp trailing off the wreck. On heavy surge days the current's strong and everything is just waving - it's so gorgeous - and the fish are hovering at the centre of the wreck staying out of the current, just like we are, and it is the most magical moment. Those twenty minutes underwater feel like years, and then when you get out, it's like it never happened. The underwater dream fades away. It's not something you can hold onto, but it is something that we can come back to over and over again and experience in our daily lives.

\section{CONCLUSION}

Thank you for reading. Bryce and I hope we have shared our fascination with the deep sea and our interest in the changing oceans in a way that is vivid, emotive, and memorable. We hope to inspire others to advocate for and affect change in the world.

Connection inspires knowledge, compassion, hope, and change. To deeply connect to ourselves and others, to understand our needs and the needs of the planet, to care for what is currently in existence and for future generations, we must pay attention. I feel a responsibility to be submerged and to tell the tale. According to the origins of "humiliate" (to make humble or bring low), I want to bring people low down to the earth; I want to draw them under, into the deep below.

We are as fragile and insignificant as a mollusc in a rock pool next to an ocean twenty million square kilometres wide - and yet we have changed the oceans beyond how we believed they could be changed. 
Immerse yourself in the natural world in whatever way you can. Wade in rock pools, snorkel in shallow depths, and scuba dive at greater ones. Enjoy the sensations of your body moving through the water. Observe marine life in their natural habitat. Work to protect it if you can. Appreciate it while it's here. Tune your ear to birdsong, to wind rushing through the trees, to the roar of the ocean in the distance. Pause. This is your life. This is our planet. Locate yourself. Know where the river is, the estuary, the ocean, the nearest mountain. Look up into the night sky, at the river of stars that is the milky way. You are here.

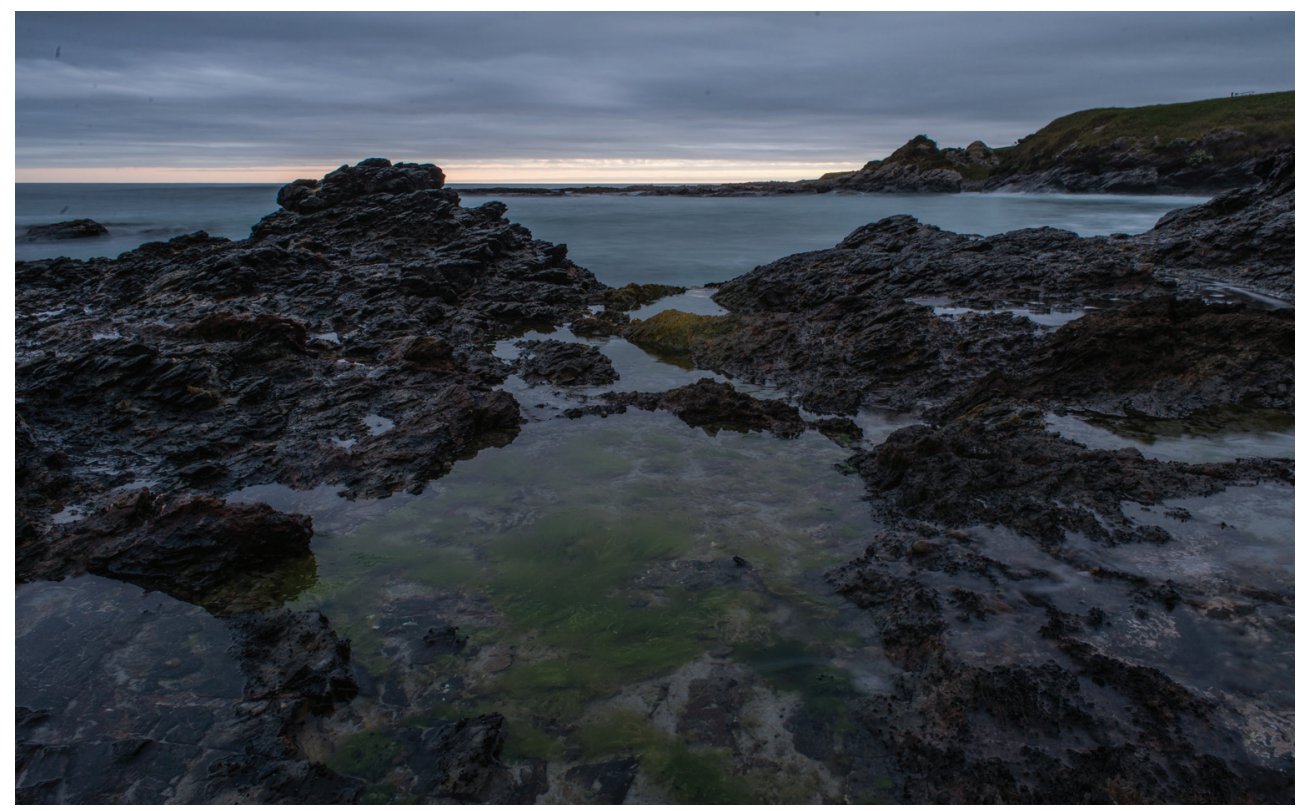

Figure 7. Rock pools at dusk. Photograph: Anne Marie Basquin.

Bryce Peebles earned his PhD in Marine Science in 2017. His research areas include deep-sea ecology, taphonomy, biomineralization, and ocean acidification.

Anne Marie Basquin is an artist and writer with a preference for underwater photography, painting and fiction. She uses her work to advocate for the oceans. She is based in New Zealand and the wider Pacific.

1. Elizabeth Kolbert, The Sixth Extinction: An Unnatural History (New York: Picador, Henry Holt and Company, 2015), 104. 